\title{
Impact of spider nevus and subcutaneous collateral vessel of chest/abdominal wall on outcomes of liver cirrhosis
}

\author{
Hongyu Li ${ }^{1}$, Ran Wang ${ }^{1}$, Nahum Méndez-Sánchez ${ }^{2}$, Ying Peng ${ }^{1}$, Xiaozhong Guo ${ }^{1}$, Xingshun Qi ${ }^{1}$
}

\author{
${ }^{1}$ Liver Cirrhosis Study Group, Department of Gastroenterology, General Hospital \\ of Shenyang Military Area, Shenyang, China \\ ${ }^{2}$ Liver Research Unit, Medica Sur Clinic \& Foundation, Mexico City, Mexico
}

Submitted: 15 November 2017

Accepted: 3 December 2017

Arch Med Sci 2019; 15, 2: 434-448

DOI: https://doi.org/10.5114/aoms.2018.74788

Copyright @ 2018 Termedia \& Banach

\begin{abstract}
Introduction: Spider nevus and subcutaneous collateral vessel of the chest/ abdominal wall are common in liver cirrhosis. This prospective study aimed to evaluate the impact of spider nevus and subcutaneous collateral vessel of the chest/abdominal wall on the outcomes of cirrhotic patients.

Material and methods: We prospectively enrolled patients with a diagnosis of liver cirrhosis consecutively admitted to our department. We recorded the number and location of spider nevi and subcutaneous collateral vessels of the chest/abdominal wall. Clinical profiles and survival were compared according to the presence of spider nevus and subcutaneous collateral vessel of the chest/abdominal wall. The study was registered (NCT02468479).

Results: Overall, 198 patients were enrolled between June 2015 and May 2016. The median follow-up duration was 350 days. The prevalence of spider nevus and subcutaneous collateral vessel of the chest/abdominal wall was $47 \%$ and $29.8 \%$, respectively. Patients with spider nevi had a significantly higher proportion of alcohol abuse (54.84\% vs. $26.67 \%, p<0.001)$. Both spider nevus and subcutaneous collateral vessel of the chest/abdominal wall were significantly associated with higher Child-Pugh $(8.35 \pm 2.19$ vs. $7.47 \pm 1.91, p=0.005 ; 8.57 \pm 2.20$ vs. $7.60 \pm 1.98, p=0.002$ ) and MELD scores $(9.91 \pm 6.41$ vs. $7.43 \pm 5.40, p=0.008 ; 10.77 \pm 6.76$ vs. $7.68 \pm 5.42, p=$ $0.003)$. The cumulative survival was not significantly different between patients with and without spider nevi of the chest/abdominal wall $(p=0.951)$. Patients with subcutaneous collateral vessels of the chest/abdominal wall had significantly worse cumulative survival $(p=0.018)$.

Conclusions: Presence of spider nevus and subcutaneous collateral vessel of the chest/abdominal wall indicated more severe liver dysfunction. Subcutaneous collateral vessel of the chest/abdominal wall should be a simple and important predictor for the overall survival of cirrhotic patients.
\end{abstract}

Key words: physical, complication, prognosis, survival, Child-Pugh.

\section{Introduction}

Spider nevus is a common sign of liver cirrhosis [1-3]. Spider nevus is so named because of its spider-like appearance in which there is a central red arteriole and radiating thin-walled vessels resembling the body and legs of a spider, respectively. In the general population, it has been reported that the presence of spider nevus is associated with thyrotox-

\author{
Corresponding author: \\ Prof. Xiaozhong Guo MD \\ Dr. Xingshun Qi MD \\ Department \\ of Gastroenterology \\ General Hospital \\ of Shenyang Military Area \\ 83 Wenhua Road \\ Shenyang, 110840 \\ Liaoning Province, China \\ Phone: +86 2428897603 \\ Fax: +86 2428851113 \\ E-mail: \\ guo_xiao_zhong@126.com, \\ xingshunqi@126.com
}


icosis and excessive estrogen, such as pregnancy and oral contraceptives. In cirrhotic patients, the underlying mechanisms of spider nevus include the disturbance of sex hormones (i.e., higher ratio of estradiol to testosterone, increased level of luteinizing hormone, and decreased level of testosterone in male patients) [4-6], angiogenesis (i.e., elevated expression of vascular endothelial growth factor and fibroblast growth factor) [7], vasodilation (increased level of substance P) [8], alcohol abuse [4], hyperdynamic circulation state [9], and liver dysfunction [4, 5]. Evidence suggests that spider nevus can predict the grade of liver fibrosis in patients with chronic liver diseases [10-12], and is closely associated with the likelihood of hepatopulmonary syndrome in patients with portal hypertension $[13,14]$.

Subcutaneous collateral vessels of the chest/ abdominal wall are also frequently observed in cirrhotic patients [15]. In the setting of portal hypertension, paraumbilical vein dilation further leads to the occurrence of subcutaneous collateral vessels of the chest/abdominal wall and even caput medusae $[16,17]$. Sometimes, the subcutaneous collateral vessel of the abdominal wall acts as the drainage vessel of intra-abdominal varices, such as stomal and jejunal varices [18, 19]. However, the clinical significance of subcutaneous collateral vessels of the chest/abdominal wall in liver cirrhosis remains unclear.

We conducted a prospective observational study to analyze the impact of spider nevus and subcutaneous collateral vessel of the chest/abdominal wall on the outcomes of patients with liver cirrhosis.

\section{Material and methods}

This was a prospective observational study. The study protocol was approved by the Medical Ethical Committee of our hospital. The human study complied with the Declaration of Helsinki. The approval number was No. k(2015)06. The study was also registered in the website clinicaltrial.gov. The register number was NCT02468479. The inclusion criteria were as follows: 1) patients with a diagnosis of liver cirrhosis; and 2) agreement to perform the physical examinations. The exclusion criteria were as follows: 1) a repeated admission; and 2) a confirmed diagnosis of malignancy. The primary endpoint was survival.

Liver cirrhosis was diagnosed based on the clinical symptoms related to liver diseases and portal hypertension, biochemical laboratory tests, liver stiffness measurement, and hepatic ultrasound, computed tomography, and/or magnetic resonance images [20]. If necessary, a liver biopsy was performed. Grades of ascites and hepatic encephalopathy were based on the practice guidelines
[21, 22]. Management of liver cirrhosis and portal hypertension related complications was based on the current practice guidelines [21-24].

At admission, three investigators (RW, YP, and $\mathrm{XQ}$ ) performed the physical examinations for all eligible patients. In the case of uncertainty, they would discuss it with two primary investigators ( $H L$ and $X G$ ). According to the number of spider nevi of the chest/abdominal wall, they were divided into $0,1-2,3-4$, and $\geq 5$. According to the location of spider nevi, they were divided into chest wall alone, abdominal wall alone, and both chest and abdominal walls. According to the location of subcutaneous collateral vessels of the chest/ abdominal wall, they were divided into chest wall alone, abdominal wall alone, and both chest and abdominal walls. Other baseline data were collected about the demographic profile, major clinical symptoms, etiology of liver cirrhosis, white blood cells, platelet count, hemoglobin, and hepatic, renal, and coagulation function. Child-Pugh and MELD scores were calculated according to the relevant formulae $[25,26]$.

Patients were followed until lost to follow-up, death, or December 31, 2016. Follow-up data were prospectively collected by two investigators (RW and XQ) from the re-admission records and by telephone contacts.

\section{Statistical analysis}

Statistical analyses were performed using SPSS statistics 17.0.0 and MedCalc 11.4.2.0 software. Continuous data were expressed as the mean \pm standard deviation and median (range) and compared using the independent $t$ test or non-parametric Mann-Whitney $U$ test. Categorical data were expressed as frequency (percentage) and compared using the Pearson $\chi^{2}$ test or Fisher's exact test. Cumulative risk was estimated by Kaplan-Meier curve analysis and compared by the log-rank test. A two-sided $p$-value of $<0.05$ was considered statistically significant.

\section{Results}

\section{Patients}

A total of 198 patients were included in the prospective study between June 2015 and May 2016. Patient characteristics are shown in Table I. The majority of patients were male $(64.6 \%)$, had a history of alcohol abuse (39.9\%) and hepatitis B virus infection (32.3\%), and were in Child-Pugh class B (51.3\%). The in-hospital mortality was $2.02 \%$ (4/198). Two patients underwent liver transplantation during follow-up. The overall mortality was $14.14 \%$ (28/198) during a mean follow-up duration of $327.5 \pm 152.97$ days (median: 350 days; range: 6-567). 
Table I. Baseline characteristics of 198 patients

\begin{tabular}{|c|c|c|c|}
\hline Variables & $\begin{array}{c}\text { No. pts. with } \\
\text { available } \\
\text { data }\end{array}$ & $\begin{array}{c}\text { Mean } \pm \text { SD or } \\
\text { Frequency (percentage) }\end{array}$ & Median (range) \\
\hline Sex (male/female), $n(\%)$ & 198 & $128(64.65) / 70(35.35)$ & \\
\hline Age [years] & 198 & $56.95 \pm 11.41$ & $56.38(26.76-88.10)$ \\
\hline \multicolumn{4}{|l|}{ Etiology of liver diseases, $n(\%)$ : } \\
\hline Hepatitis B virus infection & 198 & $64(32.30)$ & \\
\hline Hepatitis $\mathrm{C}$ virus infection & 198 & $18(9.09)$ & \\
\hline Alcohol abuse & 198 & $79(39.90)$ & \\
\hline Drug-induced liver injury & 198 & $10(5.05)$ & \\
\hline Autoimmune liver disease & 198 & $9(4.55)$ & \\
\hline Previous gastrointestinal bleeding, $n(\%)$ & 198 & $106(53.54)$ & \\
\hline Hepatic encephalopathy at admission, $n(\%)$ & 198 & $16(8.08)$ & \\
\hline Gastrointestinal bleeding at admission, $n(\%)$ & 198 & $106(53.54)$ & \\
\hline Jaundice at admission, $n$ (\%) & 198 & $36(18.18)$ & \\
\hline $\begin{array}{l}\text { Ascites at admission (no/mild/moderate- } \\
\text { severe), } n(\%)\end{array}$ & 198 & $\begin{array}{c}80(40.40) / \\
39(19.70) / 79(39.90)\end{array}$ & \\
\hline Spider nevus of chest/abdominal wall, $n$ (\%): & 198 & $93(46.97)$ & \\
\hline Number $(1-2 / 3-4 / \geq 5)$ & 93 & $\begin{array}{c}46(49.46) / \\
20(21.51) / 27(29.03)\end{array}$ & \\
\hline $\begin{array}{l}\text { Location (chest alone/abdomen alone/both } \\
\text { chest and abdomen) }\end{array}$ & 93 & $\begin{array}{c}91(97.85) / \\
0(0.00) / 2(2.15)\end{array}$ & \\
\hline $\begin{array}{l}\text { Subcutaneous collateral vessel of chest/ } \\
\text { abdominal wall, } n(\%) \text { : }\end{array}$ & 198 & $59(29.80)$ & \\
\hline $\begin{array}{l}\text { Location (chest alone/abdomen alone/both } \\
\text { chest and abdomen) }\end{array}$ & 59 & $\begin{array}{c}10(16.95) / 33 \\
(55.93) / 16(27.12)\end{array}$ & \\
\hline \multicolumn{4}{|l|}{ Laboratory tests: } \\
\hline Red blood cells $\left[\times 10^{12} / \mathrm{l}\right]$ & 197 & $3.14 \pm 0.83$ & $3.04(1.42-5.64)$ \\
\hline Hemoglobin $[\mathrm{g} / \mathrm{l}]$ & 197 & $92.18 \pm 27.71$ & $91.00(37.00-170.00)$ \\
\hline White blood cells $\left[\times 10^{9} / 1\right]$ & 197 & $5.14 \pm 3.39$ & $4.30(1.10-23.10)$ \\
\hline Platelets $\left[\times 10^{9} / \mathrm{I}\right]$ & 197 & $91.94 \pm 59.00$ & $75.00(11.00-346.00)$ \\
\hline Alanine aminotransferase [U/I] & 195 & $41.62 \pm 60.47$ & $25.52(4.61-590.00)$ \\
\hline Aspartate aminotransferase [U/I] & 195 & $62.34 \pm 80.89$ & $37.66(6.97-719.84)$ \\
\hline Alkaline phosphatase [U/l] & 195 & $126.33 \pm 105.26$ & $95.00(33.00-850.45)$ \\
\hline$\gamma$-Glutamyl transpeptidase [U/I] & 195 & $115.38 \pm 176.31$ & $46.16(9.00-981.00)$ \\
\hline Total bilirubin $[\mu \mathrm{mol} / \mathrm{l}]$ & 195 & $37.06 \pm 46.01$ & $23.40(6.40-319.90)$ \\
\hline Prothrombin time $[\mathrm{s}]$ & 193 & $16.55 \pm 3.31$ & $15.70(11.30-31.60)$ \\
\hline International normalized ratio & 191 & $1.38 \pm 0.38$ & $1.29(0.83-3.03)$ \\
\hline Activated partial thromboplastin time [s] & 192 & $40.54 \pm 5.99$ & $39.65(29.20-57.80)$ \\
\hline Albumin $[\mathrm{g} / \mathrm{l}]$ & 194 & $30.35 \pm 6.84$ & $29.70(16.10-48.10)$ \\
\hline Serum sodium [mmol/l] & 196 & $138.85 \pm 3.91$ & $138.40(120.70-151.60)$ \\
\hline Serum potassium $[\mathrm{mmol} / \mathrm{l}]$ & 196 & $3.91 \pm 0.46$ & $3.87(2.48-5.60)$ \\
\hline Blood urea nitrogen [mmol/l] & 194 & $7.57 \pm 5.88$ & $5.72(1.71-47.21)$ \\
\hline Serum creatinine $[\mu \mathrm{mol} / \mathrm{l}]$ & 194 & $78.44 \pm 65.04$ & $65.41(32.14-533.70)$ \\
\hline Child-Pugh score & 189 & $7.89 \pm 2.09$ & $8.00(5.00-14.00)$ \\
\hline Child-Pugh class A/B/C, $n$ (\%) & 189 & $\begin{array}{c}55(29.10) / \\
97(51.32) / 37(19.58)\end{array}$ & \\
\hline MELD score & 187 & $8.64 \pm 6.02$ & $7.70(-2.38-28.02)$ \\
\hline In-hospital death, $n(\%)$ & 198 & $4(2.02)$ & \\
\hline Overall death, $n(\%)$ & 198 & $28(14.14)$ & \\
\hline
\end{tabular}

SD - standard deviation, MELD - model for end-stage liver disease. 


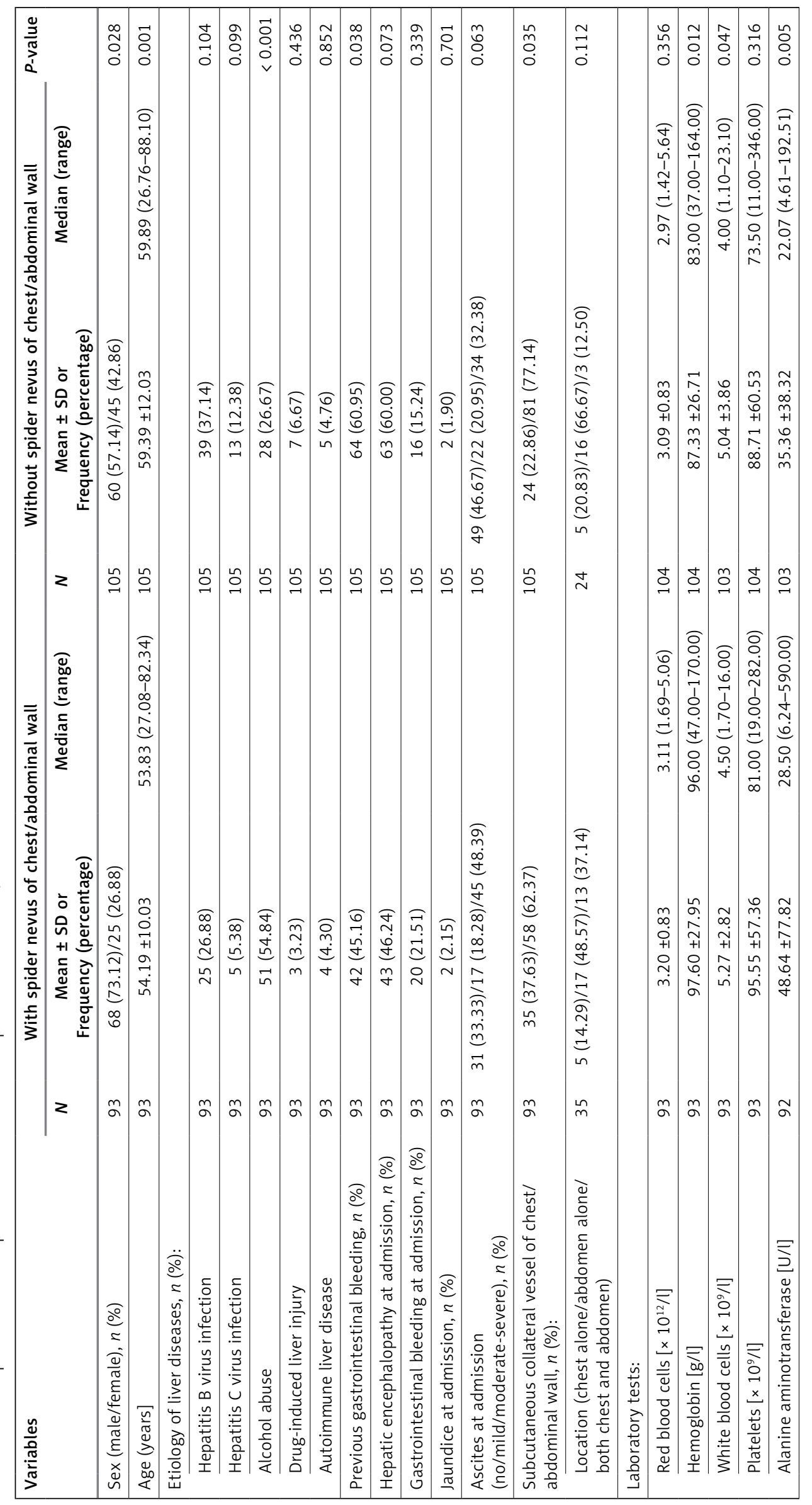




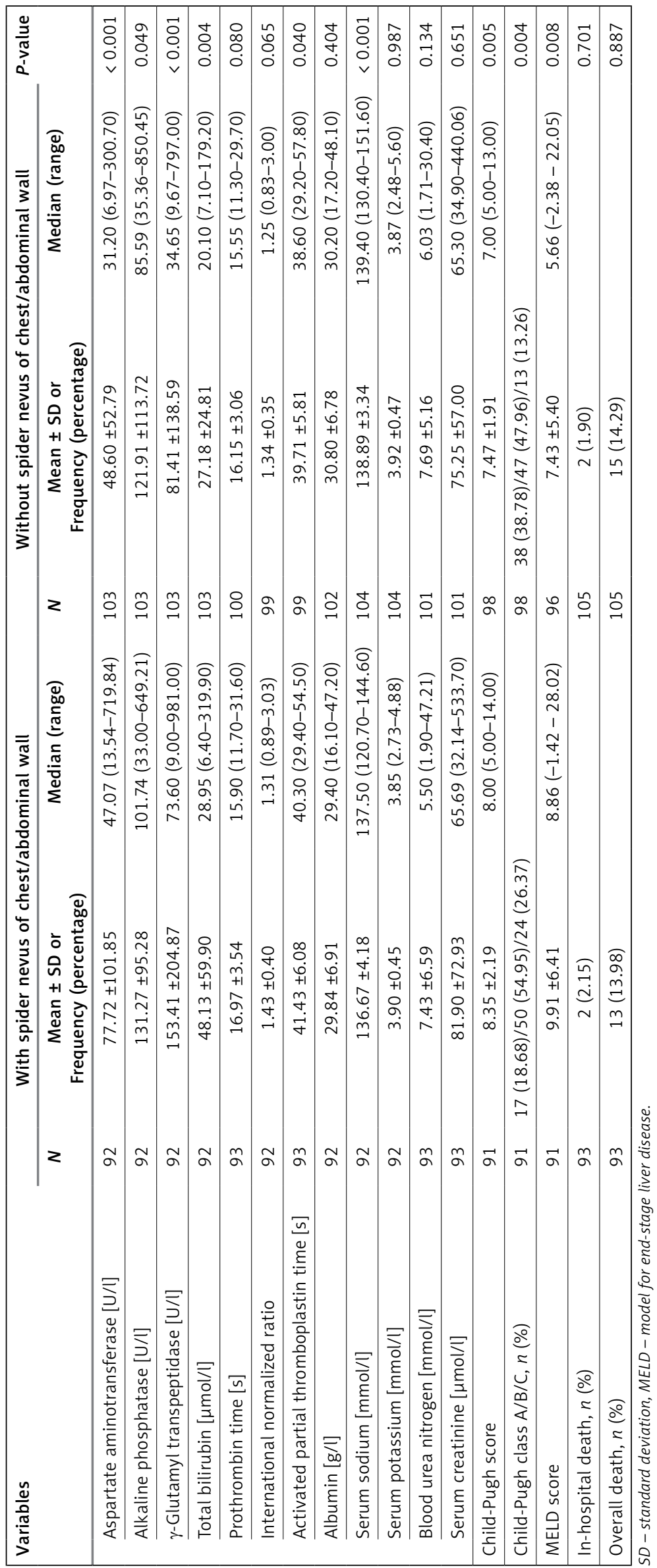


A

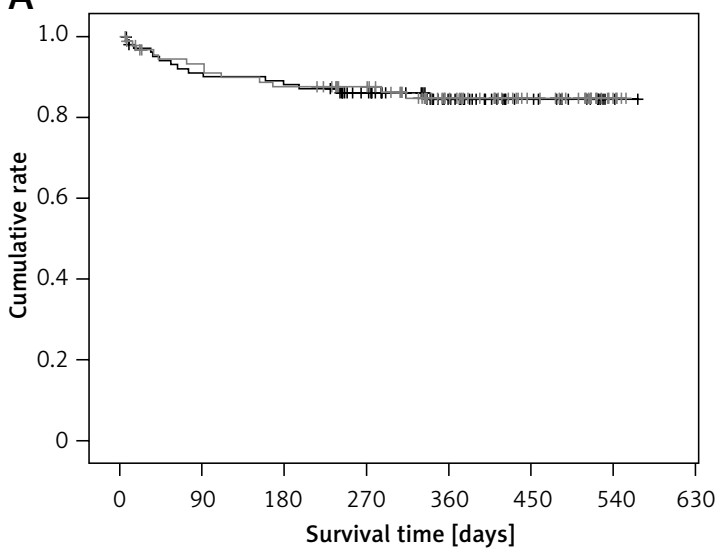

$\neg$ Without spider nevus $\neg$ With spider nevus
B

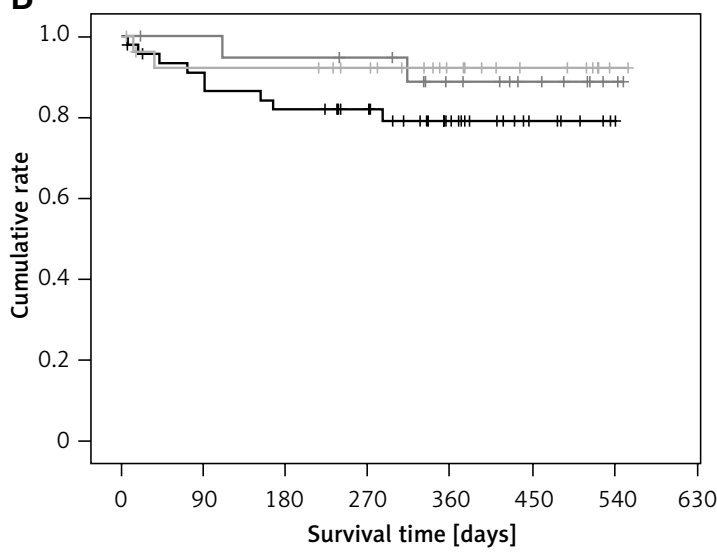

$\neg$ With 1-2 spider nevi $\quad \neg$ With 3-4 spider nevi

$\square$ With $\geq 5$ spider nevi

Figure 1. Kaplan-Meir curve regarding the impact of spider nevus on cumulative survival of cirrhotic patients. A Patients with vs. without spider nevus. B - Patients with $1-2$ vs. 3-4 vs. $\geq 5$ spider nevi of chest/abdominal wall

\section{Spider nevus of chest/abdominal wall}

The prevalence of spider nevus of the chest/ abdominal wall was $47 \%(93 / 198)$. Of the $93 \mathrm{pa}$ tients with spider nevi, $49.46 \%$ (46/93), $21.51 \%$ (20/93), and $29.03 \%$ (27/93) had $1-2,3-4$, and $\geq 5$ spider nevi, respectively. The location of the spider nevus was the chest wall alone in nearly all patients (97.85\%, 91/93).

Patients with spider nevi of the chest/abdominal wall had significantly higher proportions of male sex, alcohol abuse, subcutaneous collateral vessel of the chest/abdominal wall, and Child-Pugh classes B and C, significantly higher hemoglobin, white blood cells, alanine aminotransferase, aspartate aminotransferase, alkaline phosphatase, gamma-glutamyl transpeptidase, total bilirubin, activated partial thromboplastin time, Child-Pugh score, and MELD score, and significantly lower sodium, and were significantly younger than those without spider nevi of the chest/abdominal wall (Table II). The cumulative survival was not significantly different between patients with and without spider nevi of the chest/abdominal wall ( $p=$ 0.951) (Figure $1 \mathrm{~A}$ ).

Proportions of male sex and alcohol abuse were significantly different among patients with different numbers of spider nevi of the chest/abdominal wall (Table III). The cumulative survival was not significantly different among them $(p=0.151)$ (Figure $1 \mathrm{~B}$ ).

\section{Subcutaneous collateral vessel of chest/abdominal wall}

The prevalence of subcutaneous collateral vessel of the chest/abdominal wall was $29.8 \%$ (59/198). The location of the subcutaneous collateral vessel was the chest wall alone, the abdom- inal wall alone, and both chest and abdominal walls in $16.9 \%$ (10/59), 55.9\% (33/59), and $27.1 \%$ (16/59), respectively.

Patients with subcutaneous collateral vessels of the chest/abdominal wall had significantly higher proportions of moderate to severe ascites at admission, spider nevus, and Child-Pugh class C, significantly higher alanine aminotransferase, aspartate aminotransferase, alkaline phosphatase, $\gamma$-glutamyl transpeptidase, total bilirubin, ChildPugh score, and MELD score, significantly lower proportions of previous history of gastrointestinal bleeding and gastrointestinal bleeding at admission, and significantly lower sodium than those without subcutaneous collateral vessel of chest/ abdominal wall (Table IV). The cumulative survival was significantly worse in patients with a subcutaneous collateral vessel of the chest/abdominal wall than in those without a subcutaneous collateral vessel of the chest/abdominal wall ( $p=$ 0.018) (Figure $2 \mathrm{~A}$ ).

Age, proportion of alcohol abuse, white blood cells, platelets, and gamma-glutamyl transpeptidase were significantly different among patients with different locations of the subcutaneous collateral vessel (Table V). The cumulative survival was not significantly different among them ( $p=$ 0.532) (Figure 2 B).

\section{Discussion}

The patients enrolled in our study had several major features. First, our patients formed a group of the northeastern Chinese population with liver cirrhosis. In northeastern China, the most common etiologies of liver cirrhosis are alcohol abuse and hepatitis B virus infection [27]. Indeed, one third of our patients had a history of alcohol abuse 


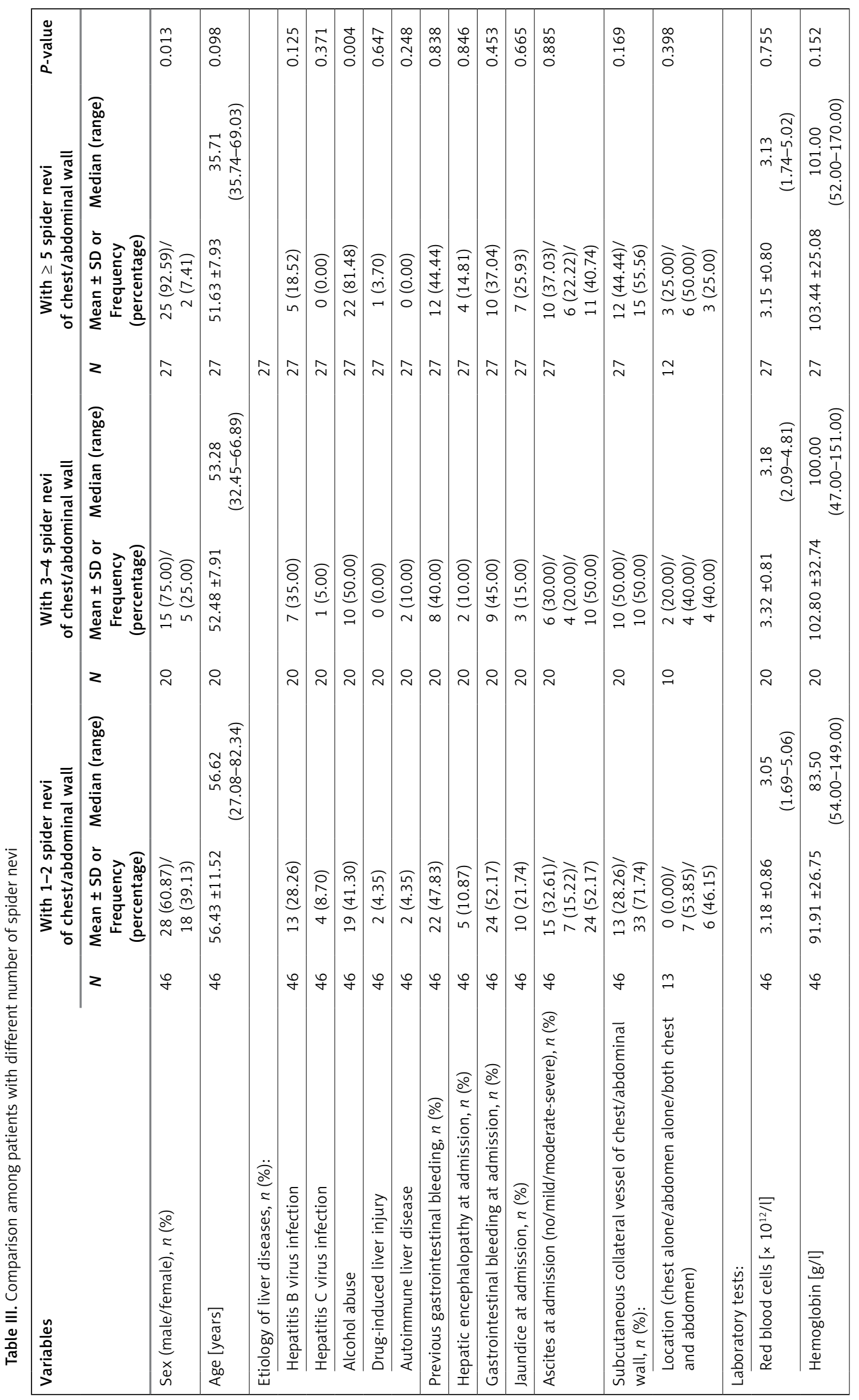




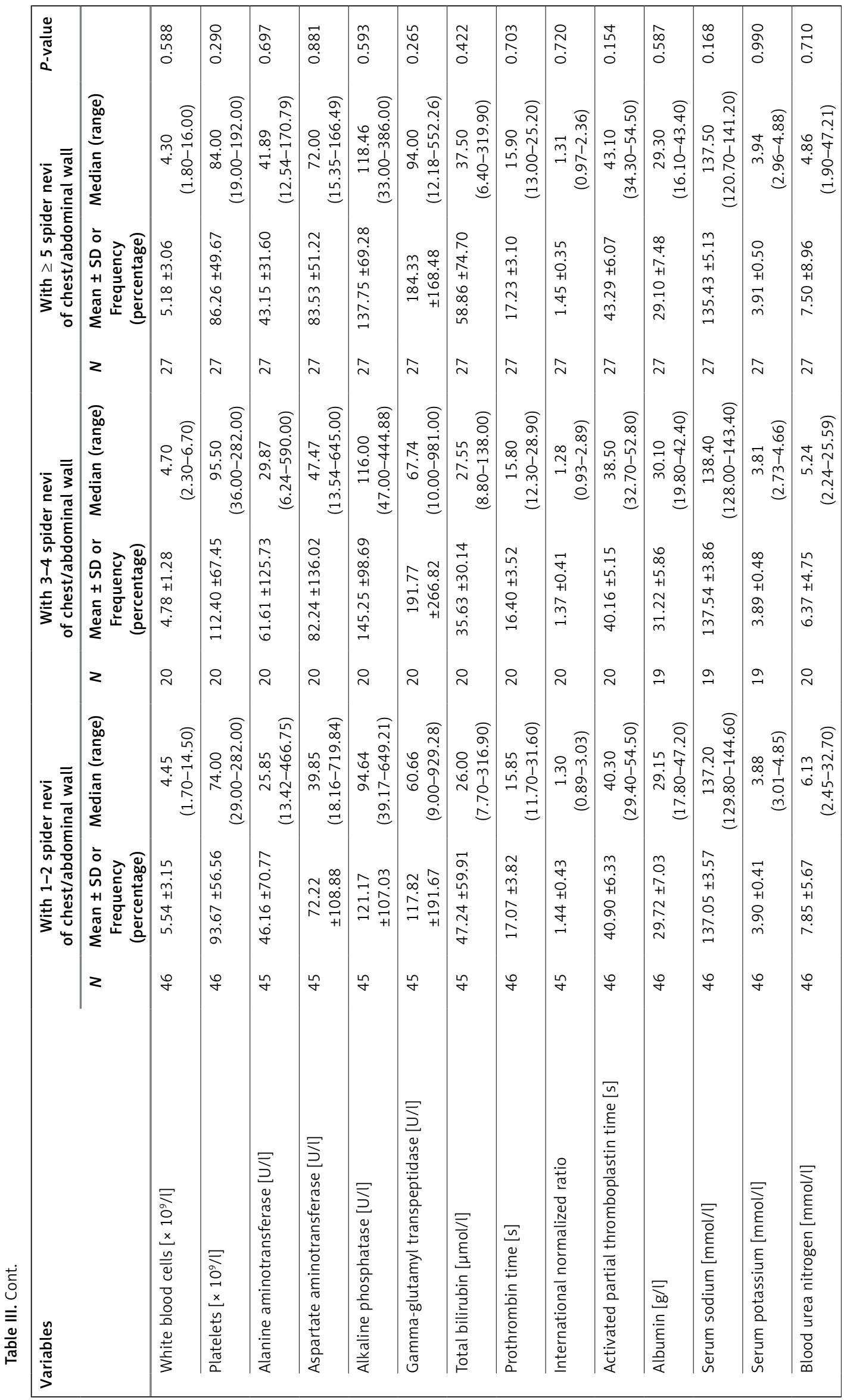




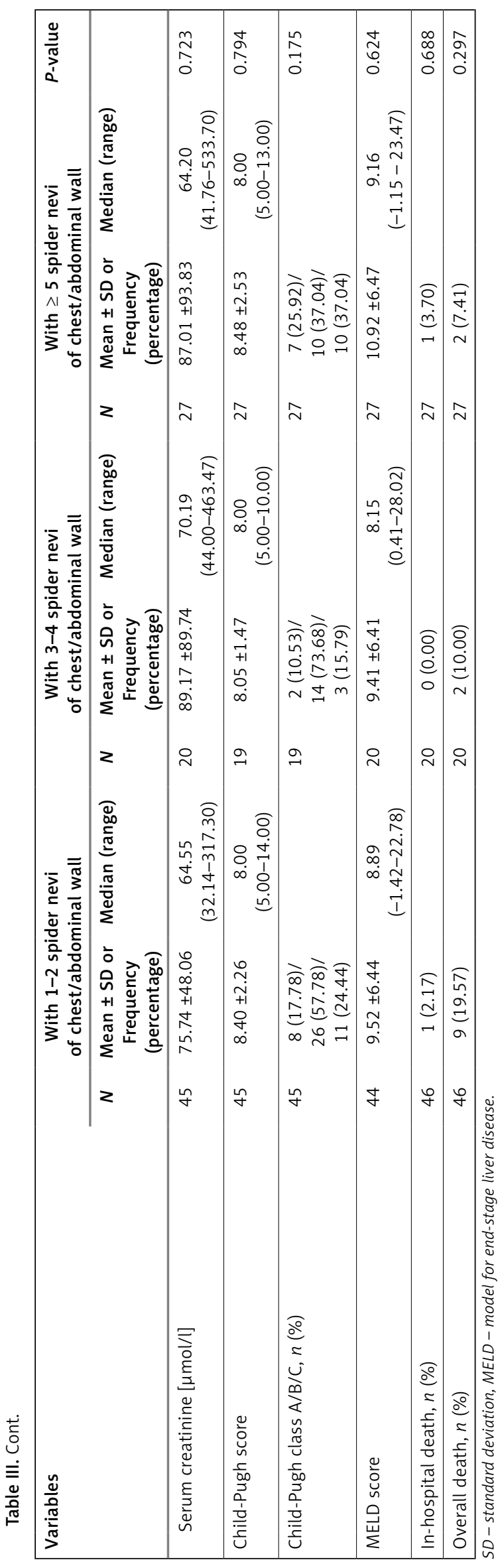

and another one third of them had hepatitis $B$ virus infection. Second, a majority of our patients were at the decompensation status, because approximately half of them had developed gastrointestinal bleeding and about two thirds of them had ascites at their admission. Third, most of our patients had relatively severe liver dysfunction, because about two thirds of them were in ChildPugh class B or $\mathrm{C}$ at their admission.

The characteristics of spider nevi and subcutaneous collateral vessels should be interpreted as follows. First, about half of cirrhotic patients had spider nevi of the chest/abdominal wall. Notably, nearly all spider nevi occurred at the chest wall; by comparison, spider nevus was hardly observed at the abdominal wall. Therefore, no comparison was performed according to the location of the spider nevus. Second, about one third of cirrhotic patients had subcutaneous collateral vessels of the chest/abdominal wall. Notably, a majority of them occurred at the abdominal walls.

In line with previous findings by Li et al. [4], our study also confirmed that alcohol abuse was significantly associated with the presence of spider nevus. More importantly, the proportion of subjects with a history of alcohol abuse increased with the number of spider nevi. Considering that alcohol abuse is more common in male patients, we can further explain the association of sex with spider nevus of the chest/abdominal wall. By contrast, the potential etiology of chronic liver diseases did not influence the development of a subcutaneous collateral vessel of the chest/abdominal wall.

Variceal bleeding is the most common type of gastrointestinal bleeding in liver cirrhosis [28-30]. Variceal bleeding is primarily associated with the degree of portosystemic pressure gradient [31], rather than coagulation abnormalities or other abnormal factors [32]. Gastrointestinal endoscopy [31], but not other alternative diagnostic methods [33-35], is the diagnostic gold standard. Our study found that the presence of subcutaneous collateral vessel of the chest/abdominal wall was negatively associated with the probability of previous gastrointestinal bleeding or gastrointestinal bleeding upon admission. Such a significant association might be explained by the fact that subcutaneous collateral vessel of the chest/abdominal wall, a type of spontaneous portosytemic shunt, might produce a lower portosystemic pressure gradient, thereby decreasing the risk of variceal bleeding. However, we must acknowledge that only a proportion of our patients underwent endoscopic examinations for the diagnosis of gastroesophageal varices. Thus, in future, well-designed studies should be performed to explore the association between subcutaneous collateral vessel of 


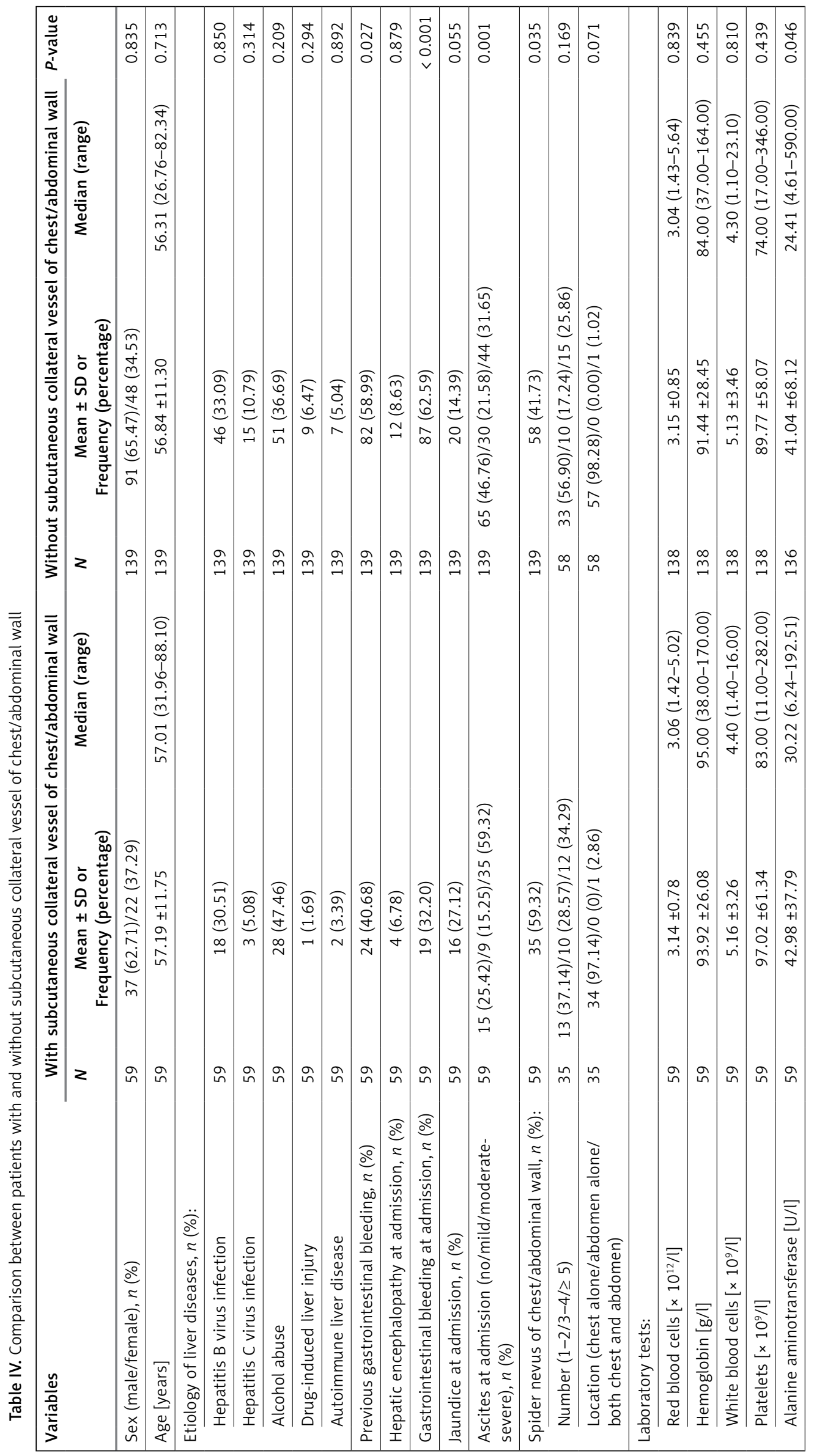



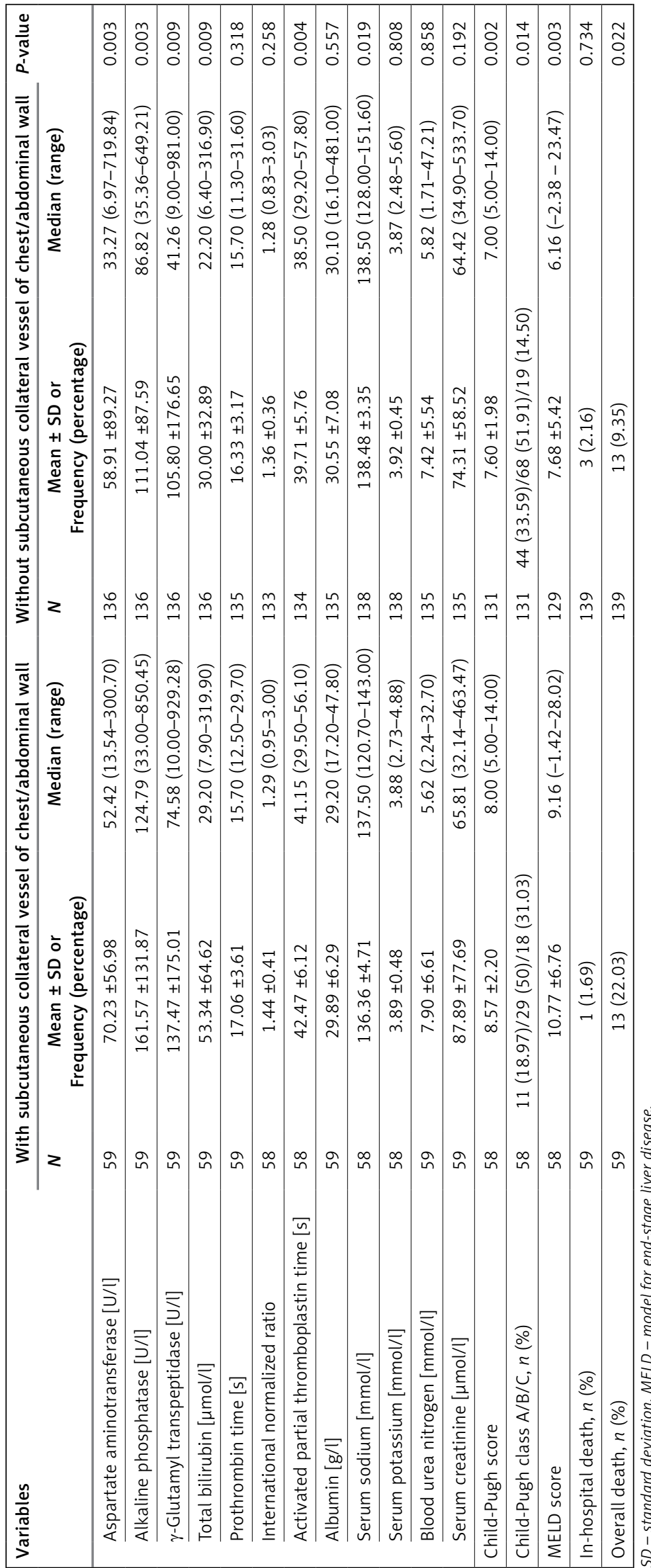
A

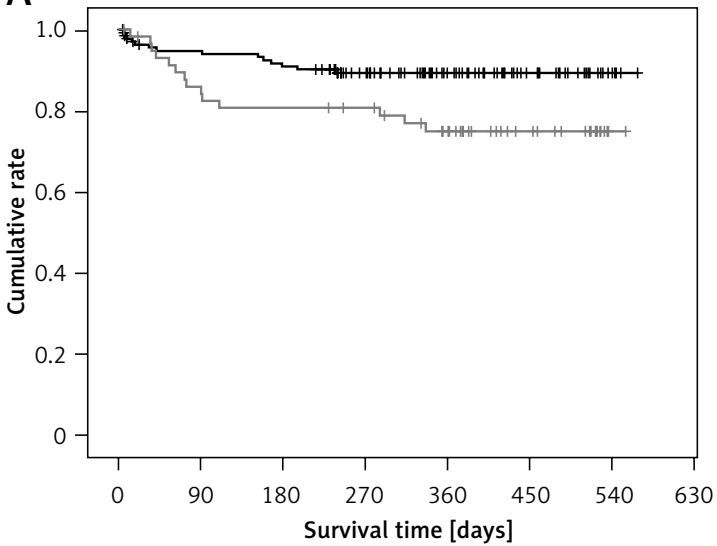

$\neg$ Without subcutaneous vein $\neg$ With subcutaneous vein
B

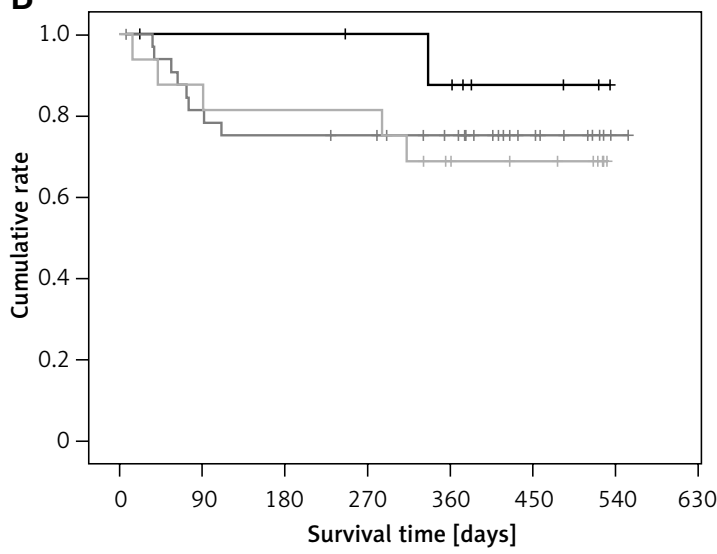

$\neg$ Chest alone $\neg$ Abdomen alone

$\square$ Both chest and abdomen

Figure 2. Kaplan-Meir curve regarding the impact of subcutaneous collateral vessel of abdominal/chest wall on cumulative survival of cirrhotic patients. A - Patients with versus without subcutaneous collateral vessel of abdominal/chest wall. B - Patients with subcutaneous collateral vessel of chest wall alone versus abdominal wall alone versus both abdominal and chest walls

the chest/abdominal wall and gastroesophageal varices or hepatic vein pressure gradient. On the other hand, in our study the association of spider nevus with the probability of gastrointestinal bleeding was obscure. A possible explanation is that spider nevus might reflect the severity of liver dysfunction and its associated disturbance of sex hormones, but not that of portal hypertension.

Both spider nevus and subcutaneous collateral vessel of the chest/abdominal wall were positively associated with the severity of liver dysfunction, such as alanine aminotransferase, aspartate aminotransferase, alkaline phosphatase, $\gamma$-glutamyl transpeptidase, total bilirubin, Child-Pugh score, and MELD score. These findings were similar to those of previous research $[4,5]$. To the best of our knowledge, no study has evaluated the impact of spider nevus and subcutaneous collateral vessel of the chest/abdominal wall on the survival of patients with liver cirrhosis. We found that neither of them was associated with in-hospital mortality. However, subcutaneous collateral vessels of the chest/abdominal wall, rather than spider nevus, could significantly predict worse overall survival during the follow-up period. Considering that spider nevus and subcutaneous collateral vessel of the chest/abdominal wall are readily available at the physical examinations, they should be considered as routine markers of liver dysfunction and death in our clinical work.

Our study had limitations. First, numerous studies have shown high prevalence of spider nevus in children regardless of chronic liver diseases [3638]. Because our patients were adults, rather than children or adolescents, we could not extrapolate from our findings to the pediatric population. Second, spider nevus is distributed all over the body. However, we only collected data regarding spider nevi and subcutaneous collateral vessels on the abdominal and chest walls, and not other body positions. Third, CT examinations might be more accurate and objective for identifying the number of subcutaneous collateral vessels of the chest/abdominal wall [15]. However, we only collected data regarding the presence of subcutaneous collateral vessel of the chest/abdominal wall on the basis of physical examinations, and not CT examinations.

In conclusion, based on the results of a prospective observational study, physical examinations regarding spider nevus and subcutaneous collateral vessel of the chest/abdominal wall should be carefully performed for early and accurate prognostic evaluation of liver cirrhosis.

\section{Acknowledgments}

Hongyu Li and Ran Wang equally contributed to the work.

This work was partially funded by the Project of the Social Development Research of the Liaoning Provincial Department of Science and Technology Agency (No. 201500184).

The abstract was partially published as a poster in the $17^{\text {th }}$ Congress of Gastroenterology China, Xi'an, China, 14-16 September 2017.

\section{Conflict of interest}

The authors declare no conflict of interest. 


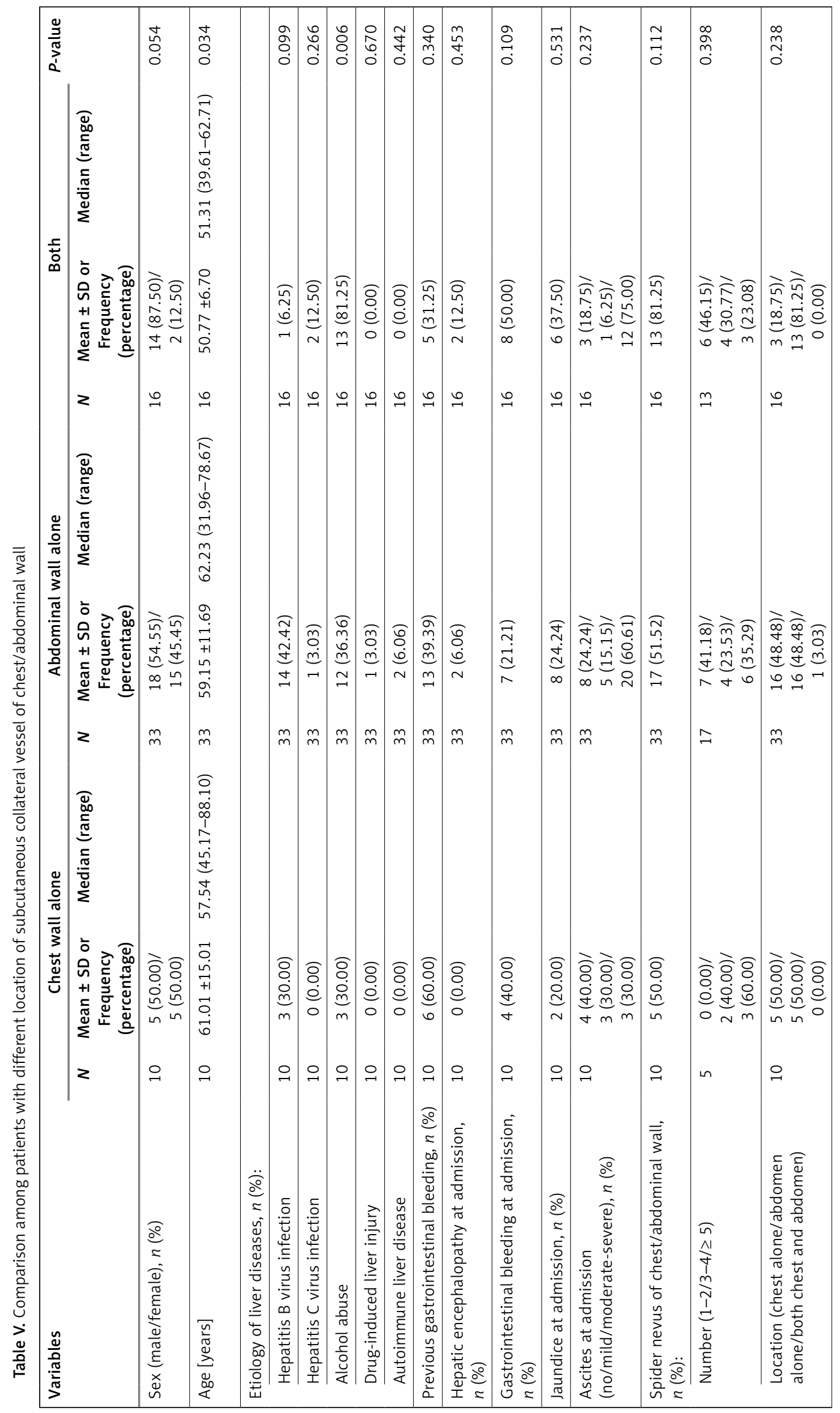




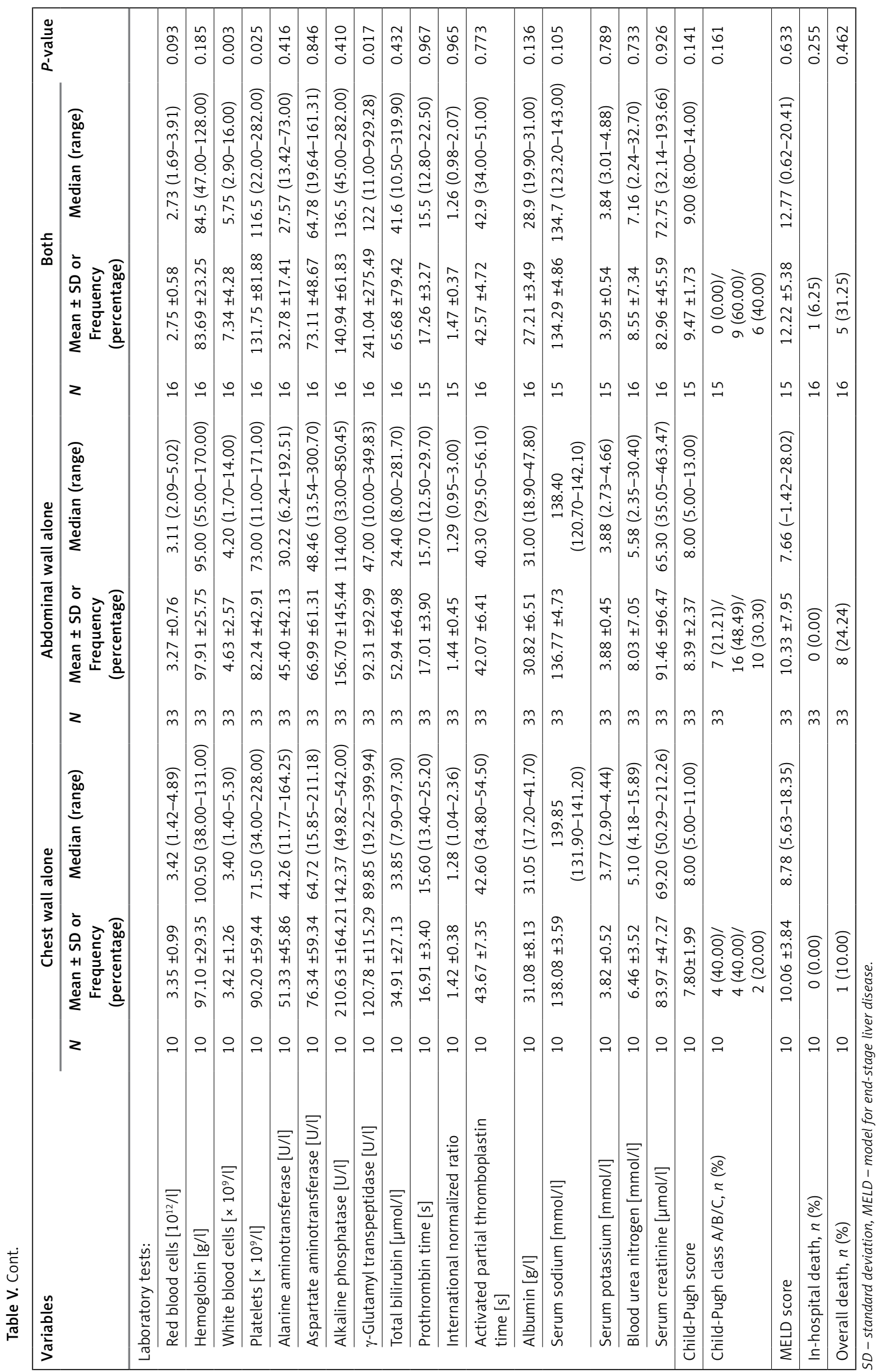


References

1. Khasnis A, Gokula RM. Spider nevus. J Postgrad Med 2002; 48: 307-9.

2. Vedamurthy $M$, Vedamurthy $A$. Spider nevi: a presenting feature of chronic liver disease. Indian J Dermatol Venereol Leprol 2008; 74: 397-8.

3. Satapathy SK, Bernstein D. Dermatologic disorders and the liver. Clin Liver Dis 2011; 15: 165-82.

4. Li CP, Lee FY, Hwang SJ, et al. Spider angiomas in patients with liver cirrhosis: role of alcoholism and impaired liver function. Scand I Gastroenterol 1999; 34: 520-3.

5. Du AS, Yang J, Lu S, Zeng JZ. [Facial skin lesions in male patients with liver cirrhosis: role of serum sex hormones and correlation with impaired liver function]. Zhonghua Gan Zang Bing Za Zhi 2013; 21: 354-8.

6. Pirovino M, Linder R, Boss C, Kochli HP, Mahler F. Cutaneous spider nevi in liver cirrhosis: capillary microscopical and hormonal investigations. Klin Wochenschr 1988; 66: 298-302.

7. Li CP, Lee FY, Hwang SJ, et al. Spider angiomas in patients with liver cirrhosis: role of vascular endothelial growth factor and basic fibroblast growth factor. World I Gastroenterol 2003; 9: 2832-5.

8. Li CP, Lee FY, Hwang SJ, et al. Role of substance P in the pathogenesis of spider angiomas in patients with nonalcoholic liver cirrhosis. Am J Gastroenterol 1999; 94: 502-7.

9. Witte CL, Hicks T, Renert W, Witte MH, Butler C. Vascular spider: a cutaneous manifestation of hyperdynamic blood flow in hepatic cirrhosis. South Med J 1975; 68: 246-8.

10. Romagnuolo J, Jhangri GS, Jewell LD, Bain VG. Predicting the liver histology in chronic hepatitis C: how good is the clinician? Am J Gastroenterol 2001; 96: 3165-74.

11. Romagnuolo J, Andrews CN, Bain VG, et al. Simple clinical variables predict liver histology in hepatitis C: prospective validation of a clinical prediction model. Scand J Gastroenterol 2005; 40: 1365-71.

12. Niederau C, Lange S, Fruhauf M, Thiel A. Cutaneous signs of liver disease: value for prognosis of severe fibrosis and cirrhosis. Liver Int 2008; 28: 659-66.

13. Younis I, Sarwar S, Butt Z, Tanveer S, Qaadir A, Jadoon NA. Clinical characteristics, predictors, and survival among patients with hepatopulmonary syndrome. Ann Hepatol 2015; 14: 354-60.

14. Varghese J, llias-basha H, Dhanasekaran R, Singh S, Venkataraman J. Hepatopulmonary syndrome - past to present. Ann Hepatol 2007; 6: 135-42.

15. Groves AM, Dixon AK. Superficial collateral veins on abdominal CT: findings in cirrhosis and systemic venous obstruction. Br J Radiol 2002; 75: 645-7.

16. Yeh HC, Stancato-Pasik A, Ramos R, Rabinowitz JG. Paraumbilical venous collateral circulations: color Doppler ultrasound features. J Clin Ultrasound 1996; 24: 359-66.

17. Pagani JJ, Thomas JL, Bernardino ME. Computed tomographic manifestations of abdominal and pelvic venous collaterals. Radiology 1982; 142: 415-9.

18. Takano M, Imai Y, Nakazawa M, et al. A case of liver cirrhosis with bleeding from stomal varices successfully treated using balloon-occluded retrograde transvenous obliteration. Clin I Gastroenterol 2016; 9: 145-9.

19. Nakata M, Nakata W, Isoda N, Yoshizawa M, Sugimoto $H$. Percutaneous retrograde sclerotherapy for refractory bleeding of jejunal varices: direct injection via superficial epigastric vein. Cardiovasc Interv Radiol 2012; 35: 203-6.

20. Schuppan D, Afdhal NH. Liver cirrhosis Lancet 2008; 371: 838-51.
21. Moore KP, Wong F, Gines P, et al. The management of ascites in cirrhosis: report on the consensus conference of the International Ascites Club. Hepatology 2003; 38: 258-66.

22. Ferenci P, Lockwood A, Mullen K, Tarter R, Weissenborn K, Blei AT. Hepatic encephalopathy: definition, nomenclature, diagnosis, and quantification: final report of the working party at the $11^{\text {th }}$ World Congresses of Gastroenterology, Vienna, 1998. Hepatology 2002; 35: 716-21.

23. de Franchis R. Revising consensus in portal hypertension: report of the Baveno $V$ consensus workshop on methodology of diagnosis and therapy in portal hypertension. J Hepatol 2010; 53: 762-8.

24. Garcia-Tsao G, Sanyal AJ, Grace ND, Carey W. Prevention and management of gastroesophageal varices and variceal hemorrhage in cirrhosis. Hepatology 2007; 46: 922-38.

25. Pugh RN, Murray-Lyon IM, Dawson JL, Pietroni MC, Williams R. Transection of the oesophagus for bleeding oesophageal varices. Br J Surg 1973; 60: 646-9.

26. Kamath PS, Kim WR. The model for end-stage liver disease (MELD). Hepatology 2007; 45: 797-805.

27. Wang FS, Fan JG, Zhang Z, Gao B, Wang HY. The global burden of liver disease: the major impact of China. Hepatology 2014; 60: 2099-108.

28. Toshikuni N, Takuma Y, Tsutsumi M. Management of gastroesophageal varices in cirrhotic patients: current status and future directions. Ann Hepatol 2016; 15: 314-25.

29. Peng Y, Qi X, Dai J, Li H, Guo X. Child-Pugh versus MELD score for predicting the in-hospital mortality of acute upper gastrointestinal bleeding in liver cirrhosis. Int J Clin Exp Med 2015; 8: 751-7.

30. Zou D, Qi X, Zhu C, et al. Albumin-bilirubin score for predicting the in-hospital mortality of acute upper gastrointestinal bleeding in liver cirrhosis: a retrospective study. Turk J Gastroenterol 2016; 27: 180-6.

31. Garcia-Tsao G, Abraldes JG, Berzigotti A, Bosch J. Portal hypertensive bleeding in cirrhosis: risk stratification, diagnosis, and management: 2016 practice guidance by the American Association for the study of liver diseases. Hepatology 2017; 65: 310-35.

32. Qi X, Ye C, Guo X. Recombinant factor VIla for variceal bleeding in liver cirrhosis: still only a hope. Arch Med Sci 2017; 13: 496-9.

33. Krok KL, Wagennar RR, Kantsevoy SV, Thuluvath PJ. Esophageal capsule endoscopy is not the optimal technique to determine the need for primary prophylaxis in patients with cirrhosis. Arch Med Sci 2016; 12: 365-71.

34. Deng H, Qi X, Guo X. Diagnostic accuracy of APRI, AAR, FIB-4, Fl, King, Lok, Forns, and Fibrolndex scores in predicting the presence of esophageal varices in liver cirrhosis: a systematic review and meta-analysis. Medicine (Baltimore) 2015; 94: e1795.

35. Deng H, Qi X, Peng $\mathrm{Y}$, et al. Diagnostic accuracy of APRI, AAR, FIB-4, FI, and King scores for diagnosis of esophageal varices in liver cirrhosis: a retrospective study. Med Sci Monit 2015; 21: 3961-77.

36. Alderson MR. Spider naevi: their incidence in healthy schoolchildren. Arch Dis Child 1963; 38: 286-8.

37. Finn SM, Rowland M, Lawlor F, et al. The significance of cutaneous spider naevi in children. Arch Dis Child 2006, 91: 604-5.

38. Wenzl JE, Burgert EO Jr. The spider nevus in infancy and childhood. Pediatrics 1964; 33: 227-32. 